\title{
Covid-19 e os Desafios Postos à Atuação Profissional em Psicologia Organizacional e do Trabalho: uma Análise de Experiências de Psicólogos Gestores
}

\author{
Adriano de Lemos Alves Peixoto ${ }^{1}$ \\ ${ }^{1}$ Universidade Federal da Bahia, BA, Brasil. \\ Daiane Rose Cunha Bentivi ${ }^{1}$ \\ ${ }^{1}$ Universidade Federal da Bahia, BA, Brasil.
}

Eveli Freire de Vasconcelos ${ }^{2}$

${ }^{2}$ Universidade Católica Dom Bosco, MS, Brasil.

\begin{abstract}
Resumo: A pandemia da Covid-19 afetou de forma significativa o modo como nos relacionamos com o mundo ao nosso redor, demandando um conjunto novo de comportamentos, conhecimentos e habilidades que nos habilitem lidar com essa situação. A psicologia, enquanto ciência e profissão, está em posição de contribuir de maneira decisiva com a sociedade para que possamos enfrentar esse desafio. Entretanto, ainda precisamos conhecer um pouco mais sobre como o psicólogo organizacional e do trabalho lida com esse tipo de situação. Desenvolvemos um estudo de casos múltiplos, analisando a experiência de três psicólogos que ocupam o cargo de gestores de recursos humanos em diferentes organizações de trabalho. Os dados foram coletados a partir do uso de diários e entrevistas qualitativas. Tomamos como base o referencial de transição de Schlossberg (1984), que se volta à compreensão de processos adaptativos em situações de mudança, a fim de analisar a forma como esses profissionais estão lidando como este momento de crise. Foi possível identificar os principais gatilhos que dão início ao processo de transição, bem como alguns dos recursos usados pelos profissionais de psicologia organizacional e do trabalho (POT) para melhor lidar com a situação. Essa abordagem permitiu perceber que, ao longo do período estudado, os profissionais enfrentaram diferentes transições e que a interação entre recursos pessoais e organizacionais é capaz de estabelecer um maior controle sobre o processo. Os achados sugerem que, em situação de crise, a busca por conhecimentos científicos é uma das principais estratégias usadas pelos psicólogos de POT, reforçando o duplo estatuto de ciência e profissão de nossa área.
\end{abstract}

Palavras-chave: Covid-19, Psicologia organizacional e do trabalho, Transição.

\section{Covid-19 and the Challenges Posed to Organizational and Work Psychologists: an Analysis of the Experiences of Psychologists in Managerial Positions}

\begin{abstract}
The Covid-19 pandemic has significantly affected the way we relate to the world around us, requiring a new set of behaviors, knowledge and skills that enable us to deal with this situation. Psychology as a science and profession is in a position to make a substantive contribution to society so that we can face this challenge. However, we still need to know a little more about how work and organizational psychologist deals with this type of situation. We developed a multiple case study, analyzing the experience of three psychologists who occupy the position of human resource managers in different work organizations. Data were collected through the use of diaries and qualitative interviews. We use Schlossberg's (1984) transition framework, originally developed as a tool to understanding adaptive processes in situations of change, in order to analyze how these professionals are dealing with this moment of crisis. It was
\end{abstract}


possible to identify the main triggers that initiate the transition process, as well as some of the resources used by work and organizational psychology (WOP) professionals to better deal with the situation. This approach allowed us to realize that over the period studied, professionals faced different transitions and that the interaction between personal and organizational resources is able to establish greater control over the process. The findings suggest that in a crisis situation, the search for scientific knowledge is one of the main strategies used by WOP psychologists, reinforcing the dual status of science and profession in our area.

Keywords: Covid-19, Work and Organizational Psychology, Transition.

\title{
El Covid-19 y los Retos del Desempeño Profesional en Psicología Organizacional y del Trabajo: un Análisis de las Experiencias de los Psicólogos Directivos
}

\begin{abstract}
Resumen: La pandemia de Covid-19 ha afectado significativamente la forma con la cual nos relacionamos con el mundo que nos rodea, requiriendo un nuevo conjunto de comportamientos, conocimientos y habilidades que nos permitan lidiar con la situación actual. La psicología como ciencia y profesión está en condiciones de hacer un aporte decisivo a la sociedad para que podamos afrontar este reto. Sin embargo, nos falta saber un poco más sobre cómo el psicólogo organizacional afronta este tipo de situación. Desarrollamos un estudio de caso múltiple, analizando la experiencia de tres psicólogos que ocupan el cargo de jefes de recursos humanos en distintas organizaciones laborales. Los datos se recopilaron mediante el uso de diarios y entrevistas cualitativas. Utilizamos el marco de transición de Schlossberg (1984), que comprende los procesos adaptativos en situaciones cambiantes, con el fin de analizar cómo estos profesionales están lidiando con este momento de crisis. Fue posible identificar los principales detonantes que inician el proceso de transición, así como algunos de los recursos que utilizan los profesionales de psicología de las organizaciones y del trabajo (POT) para afrontar mejor la situación. Este enfoque permitió darnos cuenta de que durante el período estudiado los profesionales enfrentaron diferentes transiciones y que la interacción entre los recursos personales y organizacionales es capaz de establecer un mayor control sobre el proceso. Los hallazgos sugieren que en una situación de crisis la búsqueda del conocimiento científico es una de las principales estrategias utilizadas por los psicólogos de POT, reforzando la dualidad de la ciencia y la profesión en nuestra área.

Palabras clave: Covid-19, Psicología de las Organizaciones y del Trabajo, Transición.
\end{abstract}

\section{Introdução}

Ao longo da história humana, frequentemente nos deparamos com eventos que marcam uma era. Muitas vezes não exatamente em função de suas características intrínsecas, mas porque eles representam um conjunto muito mais amplo de processos e rupturas históricas, apresentando-se como símbolos ou marcos de um período. Foi assim, por exemplo, com o assassinato do Arquiduque Ferdinando de Sarajevo, em 1914, que marcou o início da Primeira Grande Guerra e, com ela, a chegada definitiva do século XX. Da mesma forma, temos a queda do muro de Berlim, em 1989, que sinalizou o final da Guerra Fria e, com ela, o próprio século XX (Hobsbawn, 1994).

Neste início de década, é possível que estejamos diante de um fenômeno com estas mesmas características: a pandemia da Covid-19. Aventamos uma possibilidade e não expressamos uma certeza, pois ainda não temos o distanciamento histórico necessário para avaliar de forma adequada a extensão e a profundidade de seu impacto e o quanto suas consequências perdurarão no futuro. De qualquer forma, podemos perceber que estamos diante de um evento que provavelmente marcará toda uma 
geração. Um ponto de inflexão em nossa trajetória. No mundo do trabalho, por exemplo, a pandemia tem impacto direto na forma como organizamos o trabalho e, principalmente, na maneira como consumimos bens e serviços.

Como situação extrema, a pandemia evidenciou nossas qualidades, aquilo que nos caracteriza como seres humanos. Ao mesmo tempo, explicitou nossos defeitos, amplificados nesse contexto marcado pelo medo e pela incerteza. Ela nos mostrou que não estávamos preparados para sua chegada, seja como indivíduos, seja como profissão ou mesmo como sociedade. A pandemia testa, mostra aquilo que sabemos, o que desconhecemos e o que escolhemos não ver. Desde seu início ficou patente que, para além dos cuidados físicos necessários ao enfrentamento dos processos infecciosos produzidos pelos organismos físicos, havia a necessidade de lidar com as consequências psicossociais que emergiram dessa nova condição, evidenciando a importância da psicologia em todas as suas dimensões e espaços de atuação.

Ainda que em seu conjunto a psicologia dispusesse de conceitos e técnicas que permitiam uma atuação decisiva nesse cenário, esse conhecimento estava disponível e localizado em campos específicos de nossas práticas e, portanto, de uso limitado, como, por exemplo, no campo das emergências, riscos e desastres. Da noite para o dia, fomos obrigados a nos apropriar desse conhecimento e adaptá-lo para uso generalizado. Como profissionais de psicologia, fomos arrancados de nossas zonas de conforto, nas quais as nossas velhas e conhecidas práticas já não davam conta de responder às emergentes necessidades que essa nova realidade impõe. Em meio a um contexto marcado pelo medo do contágio (e, consequentemente, da morte) e de grande incerteza, rapidamente tivemos que nos reinventar, ver a realidade através de novas lentes e desenvolver novos repertórios comportamentais e novas bases conceituais. De outra forma, não seríamos capazes de oferecer à sociedade o suporte que ela necessitava e esperava de nossa profissão.

Porém, como se deu esse processo de adaptação do profissional de psicologia a essa nova realidade? Que estratégias utilizou? Quais os desafios que enfrentou? Como se sentiu ao longo desse período? Essas são algumas perguntas para as quais ainda não temos respostas e que vão além das experiências individuais. Tudo ainda é muito recente e somente agora as primeiras pesquisas começam a ser publicadas e o conhecimento começa a ser sistematizado. Por isso, um desafio importante de nossa profissão, neste momento, consiste em compreender como os profissionais de Psicologia estão lidando com a pandemia, para assim retirar as lições aprendidas e melhor atender às demandas da sociedade.

Nesse contexto, nosso olhar se volta ao profissional da psicologia que atua em organizações de trabalho. Ainda que durante a pandemia muita atenção tenha se voltado para o trabalho realizado em casa (home office), uma parte importante das empresas continuaram a operar com algum grau de presencialidade. Suas atividades eram de alguma forma essenciais à manutenção da vida social ou não podiam ser executadas longe do local onde elas originariamente estavam planejadas e, sobre elas, pouco sabemos. Diante dessa condição objetiva da realidade, emergem as questões: Quais os desafios postos aos profissionais psicólogos no contexto das organizações diante dessa realidade? Como os profissionais de psicologia organizacional e do trabalho lidaram como essa situação? Como suas atividades foram adaptadas neste contexto? Quais os fatores que impactam em sua atuação? Essas são algumas das questões que buscamos compreender um pouco mais neste artigo.

\section{Exercício profissional em POT}

Toda vez que enfrentamos eventos transformadores em nossas vidas, a ameaça que muitas vezes os acompanham se constitui como uma oportunidade para novas aprendizagens. Com a nossa profissão se passa a mesma coisa. Para que possamos manter a relevância social de nossa prática, faz-se necessário que estejamos em permanente desenvolvimento, ajustando nossa atuação profissional às demandas e necessidades de uma sociedade em constante transformação. Ao longo de seu percurso histórico, a psicologia organizacional e do trabalho (POT) passou por um vasto conjunto de mudanças. Desde sua origem voltada ao trabalho no contexto industrial, no início do século do século XX, passando pela descoberta de um novo objeto de estudo e investigação nos anos 1950 (as organizações) (Peixoto \& Bastos, 2019), até os dias atuais, a área ampliou seu foco de atuação, incorporou diferentes metodologias e olhares, descobriu novos objetos. Entretanto, uma característica básica pode ser observada ao longo de sua história, uma profunda sinergia entre os domínios da ciência 
e da profissão, caracterizando aqui o que chamamos de uma profissão de base científica (Renteria, Peixoto, \& Bastos, 2020).

A partir da análise dessas dimensões, é possível identificar que existem tensões entre o campo científico e o profissional. Não que isso seja necessariamente ruim, uma vez que, em profissões de base científica, isso pode servir como um elemento dinamizador. Essa dualidade desencadeia um processo de autorreflexão que pode servir como um estímulo tanto para novas investigações quanto ao desenvolvimento de novas práticas. Um exemplo desse tipo de tensão pode ser percebido nos estudos que descrevem o exercício profissional dos psicólogos de POT no país. Eles indicam que a maioria desses profissionais se mantém atuando nos subcampos ligados às organizações e à gestão de pessoas, notadamente, o recrutamento e a seleção de pessoas, avaliação de desempenho, treinamento e ações ligadas ao comportamento organizacional (Bastos, Gondim, \& Rodrigues, 2010; Bastos, \& Rodrigues, 2014; Gondim, Bastos \& Peixoto, 2010).

Já no campo acadêmico, é possível observar uma situação semelhante, com o predomínio de pesquisas que abordam temas que se relacionam com uma agenda própria, deixando de lado questões técnicas do trabalho (Campos, Duarte, Cezar, \& Pereira, 2011). Assim, a produção de conhecimento se volta principalmente para temáticas ligadas ao comportamento organizacional, a construção e a avaliação de medidas, relações de trabalho e saúde do trabalhador. Um ponto importante acerca dessas pesquisas é que poucas apresentam a descrição e a análise de intervenções práticas em POT. A baixa incidência de pesquisas desse tipo indica uma escassa interação entre a ciência e a profissão, resultando em uma situação na qual encontramos um largo arcabouço teórico que muitas vezes não mostra sua relevância prática e social, bem como um fazer de nível mais instrumental, caracterizado por baixa elaboração e reflexão (Anderson, Herriot, \& Hodgkinson, 2001), que muitas vezes se produz e reproduz ao sabor de modismos sem que esteja ancorado em conhecimentos científicos sólidos (Renteria et al., 2020).

As discrepâncias observadas entre teoria e prática, aliadas ao predomínio de profissionais executando principalmente atividades operacionais e de baixa complexidade, certamente contribui para uma visão incompleta da identidade profissional.
Essa discrepância pode ser explicada por diversos fatores, como, por exemplo, a deficiência na formação do psicólogo para atuar no contexto do trabalho, a necessidade de apropriação de bases teóricas e filosóficas para alicerçar a prática e a necessidade de inovação na atividade profissional do psicólogo no contexto do trabalho (Coelho-Lima, Costa \&, Yamamoto, 2011). Essa lacuna na formação e na articulação entre teoria e prática se reflete da dificuldade de profissionais que atuam no contexto das organizações de trabalho em lidar com situações de crise, como é o caso que experienciamos atualmente diante da pandemia da Covid-19, em função de limitações nos repertórios comportamentais. Crise pode ser compreendida como "um evento de baixa probabilidade e alto impacto que ameaça a viabilidade da organização e é caracterizada pela ambiguidade de causa, efeito e meios de resolução, bem como pela crença de que as decisões devem ser tomadas rapidamente" (Pearson \& Clair, 1998, p. 60).

O contexto, que em geral sempre foi visto como uma variável de menor importância na definição e delimitação da atividade desse profissional, ganha protagonismo. Isso aponta para uma tendência que já vinha se delineando no campo, mas que vem se acentuando em tempos recentes, que é a necessária atenção às transformações do mundo do trabalho e da sociedade em geral. Essa situação demanda uma maior atenção das competências necessárias para atuação em contextos em transformação, como, por exemplo, adaptabilidade, capacidade de lidar com a imprevisibilidade e incertezas, gerenciamento de crises externas e internas que ameaçam o desempenho dos trabalhadores e das organizações, dentre outros.

É sabido que é por meio do planejamento e da gestão que as organizações conseguem melhor se preparar para lidar com eventos inesperados e disruptivos, a fim de evitar consequências mais graves. Porém, tradicionalmente, os profissionais que atuam no campo da gestão de pessoas em geral e, especificamente os psicólogos, costumam não ser adequadamente preparados para lidar com esse tipo de situação. $O$ panorama de crise que se instaurou diante do avanço da Covid-19 se soma e potencializa os problemas já existentes nas organizações de trabalho, ampliando seus impactos sobre os trabalhadores e as organizações.

A literatura nacional sobre a atuação profissional em POT diante da pandemia de Covid-19 ainda 
são escassas. Nesse cenário, merecem destaque os três volumes da Coleção Retrato da Psicologia Brasileira no Cenário da Covid-19, publicados pela SBPOT (Bentivi, 2020; Moraes, 2020; Queiroga, 2020). Já na literatura internacional, as primeiras publicações giram em torno de três temas principais: o impacto das transformações organizacionais nos trabalhadores (Carnevale \& Hatak, 2020); a saúde ocupacional de trabalhadores que estão no front de atendimento, especialmente na área da saúde (Labrague \& Los Santos, 2020); e sobre o home office compulsório e suas reverberações na vida do trabalhador (Baert, Lippens, Moens, Sterkens, \& Weytjens, 2020; Novitasari, Sasono, \& Asbari, 2020). Diante do exposto, é possível observar que as primeiras pesquisas se relacionam com questões ligadas à saúde e ao bem-estar do trabalhador, tema esse que apresentou um crescimento significativo nesse período (Wiedemann, n.d.)

Para responder às demandas trazidas pela Covid-19, é necessário que os psicólogos do trabalho e da organização atuem no sentido de aplicar o conhecimento do campo para promover, de forma complementar, buscando uma melhoria no bem-estar dos indivíduos no trabalho e atuando no gerenciamento de riscos nas organizações (Molino et al., 2020). Nesse sentido, necessitamos de um conhecimento teórico que nos ajude a compreender e a manejar os desafios que se colocam para a atuação profissional. No âmbito dessa discussão, propomos que o referencial de transição de Schlossberg $(1981,1984)$ nos auxilie nessa tarefa.

O referencial de transição foi originalmente desenvolvido por Nancy Schlossberg $(1981,1984)$ no âmbito da psicologia do aconselhamento. Ela estava preocupada em compreender como indivíduos mudam ao longo do tempo e como são afetados nesse processo. Seu modelo propõe que o importante é avaliar a forma como as diversas transições que uma pessoa enfrenta ao longo da vida são percebidas. Partindo de uma perspectiva desenvolvimental, ela sugere que cada pessoa passa por um conjunto específico de experiências de vida, sendo que cada uma delas abre, potencialmente, novos caminhos e possibilidades, em um processo de diferenciação. Por outro lado, esses processos de desenvolvimento precisam ser compreendidos no contexto específico no qual ocorrem. Escolhas, recursos, aspirações, padrões de vida, modelos de referência, possibilidades de atuação, todos eles ocorrem dentro dos limites que são estabelecidos pelo contexto.

O processo de transição tem seu início quando a pessoa se depara com uma situação que traz em si algum tipo de mudança na forma como ela experimenta algum aspecto significativo de sua existência. Essa situação exige um processo de adaptação ao novo, que usualmente envolve desenvolver novos papéis sociais, modificar repertórios comportamentais ou assumir uma nova posição na vida. Para que isso ocorra, é necessário que o indivíduo mobilize recursos pessoais que lhe permitam lidar com a situação desconhecida (Peixoto, Côrtes \& Bastos, 2020). Adultos em processo de transição normalmente necessitam de algum tipo de ajuda, uma vez que essas experiências costumam desencadear o medo e a insegurança. São exemplos de transições as mudanças de carreira, a entrada no mundo do trabalho e os diversos aspectos das relações interpessoais, tais como casamento, separação, nascimento e morte. Ainda que o processo de mudança seja individual, existe uma estrutura básica na transição que é bastante estável. E é justamente esse o ponto que a torna um referencial útil para que possamos compreender a realidade.

O processo de transição se caracteriza como um ajuste adaptativo que envolve basicamente três etapas distintas, conforme podemos ver na Figura 1 abaixo: a) aproximação da transição, é nesse momento que a pessoa se dá conta de que algo está para mudar em sua vida. Ela identifica a natureza da mudança e avalia os impactos potenciais em sua vida. Mudanças antecipadas permitem planejamento e avaliação. Mudanças não antecipadas, normalmente, desencadeiam processos de adaptação mais custosos pois não permitem que o indivíduo se prepare para seu enfrentamento; b) lidando com a transição, nesse ponto os indivíduos lançam mão de seus recursos de coping de modo a lidar com as consequências de sua situação. O modelo propõe quatro fatores principais que influem nessa capacidade do indivíduo: a situação (o momento em que a transição ocorre), o self (as características individuais), o suporte (percebido e disponível) e estratégias (com a pessoa navega pela situação); c) assumindo o controle, aqui o ponto focal consiste em compreender que, ainda que não seja possível controlar aquilo que acontece com o indivíduo, é possível, por meio da mobilização de seus recursos de coping, gerenciar ou manejar os efeitos da transição em maior ou menor grau. 


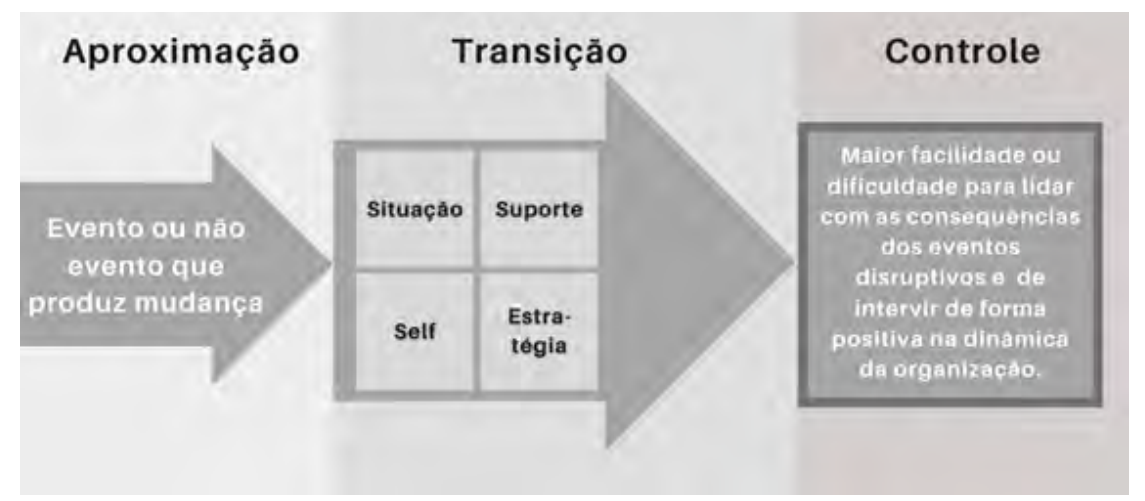

Figura 1.

Referencial de transição.

Ainda que esse referencial tenha sido originalmente pensado para análise e compreensão de indivíduos em transição, acreditamos que ele possa ser também apropriado para entendermos indivíduos em transição nas organizações de trabalho, de um modo geral, ou como os psicólogos lidam com os impactos produzidos pela Covid, em nosso caso específico.

\section{Método}

Este é um estudo exploratório, descritivo, de abordagem qualitativa e foi realizado por meio de estudo de casos múltiplos (Yin, 2009). Durante um período de 16 semanas (de 16 de março a 5 de julho), três psicólogos registraram suas experiências, sentimentos e emoções, nas reações e relacionadas às suas atuações profissionais durante a pandemia. As narrativas dos participantes foram analisadas em duas etapas. Na primeira, se buscou compreender os desafios e a trajetória de cada profissional diante das atividades diárias de gestão de pessoas, durante a pandemia. Nesse primeiro momento, estivemos atentos à identificação de padrões de respostas comuns que pudessem emergir durante a pandemia. Ao mesmo tempo, buscamos compreender como características individuais se relacionaram e interagiram com características organizacionais, modulando a ação do profissional nesse período.

Na segunda etapa, realizamos uma entrevista com o objetivo de aprofundar questões que julgássemos importantes e que eventualmente não tivessem sido adequadamente contempladas nos registros dos diários. Aqui comparamos a narrativa dos três casos e categorizamos as falas da entrevista com base na percepção dos profissionais sobre: quais foram os eventos, pontos críticos que demarcaram esse período? O que mudou em sua forma de atuação? Percebeu diferenças no contato com os trabalhadores? Qual o maior desafio para atuação?

\section{Instrumentos}

Este estudo se baseia em dois tipos de instrumentos principais: diários qualitativos e entrevista qualitativa individual. Um tema frequentemente negligenciado nos estudos organizacionais diz respeito ao efeito do tempo sobre variáveis relevantes. Quando adotamos surveys em pesquisas de corte transversal, focamos na variabilidade interpessoal (ou intersubjetiva) de um construto qualquer. Ou seja, aquilo que varia entre indivíduos. Com isso, pouca atenção tem sido dada a como os fenômenos psicológicos e sociais variam no tempo em relação a um mesmo indivíduo ou grupo social (Abbad \& Carlotto, 2016), ainda que o tempo seja uma variável relevante na compreensão de questões relacionadas ao mundo do trabalho (Sonnentag, 2012). Isso justifica a opção de utilizar uma técnica que permitisse observar como os profissionais de psicologia reagiam ao longo do tempo em suas atividades profissionais.

O diário é uma técnica de autorrelato geralmente utilizada para avaliar como estados fisiológicos, psicológicos ou mesmo sociais se alteram ao longo do tempo (Breakwell, 2010). Partimos do pressuposto de que diferentes indivíduos inseridos em contextos sociais diferentes experimentariam a realidade de forma diversa, da mesma maneira que mobilizariam distintos recursos pessoais, organizacionais e individuais ao longo desse processo. Como essas experiências variam (flutuam) ao longo do tempo em função de seu contexto (Ohly, Sonnentag, Niessen, \& Zapf, 2010). Para Bolger, 
Davis e Rafaeli (2003), o uso de diários permite capturar aspectos importantes da experiência humana que ocorrem em seu contexto natural e espontâneo, minimizando a probabilidade da retrospecção que emerge quando alguém fala ou narra acontecimentos que já estão mais distantes no tempo, sendo necessário reconstruir e integrar elementos em uma narrativa coerente. Seguimos ainda a sugestão de Breakwell (2010) e utilizamos a técnica da entrevista individual com o objetivo de complementar as informações coletadas a fim de obtermos uma descrição mais rica, completando informações e esclarecendo pontos importantes e eventualmente não cobertos nos autorregistros.

Como procedimento de análise, utilizamos uma técnica mista que envolve a síntese de casos cruzados, como proposta por Yin (2009) para análise de casos múltiplos. Ela é especialmente recomendada quando os estudos são conduzidos de maneira independente baseando-se na ideia de síntese-agregação de dados. Essa abordagem é utilizada na primeira parte da análise dos dados. Complementamos o processo analítico fazendo uso da codificação temática proposta por Strauss (1987). Essa é uma estratégia utilizada para comparar as diferentes percepções dos participantes com o uso de tópicos pré-definidos e diretamente associados aos objetivos do estudo e à natureza dos grupos, em um procedimento semelhante àquele utilizado por Ribeiro, Peixoto e Bastos (2019) no estudo de diferentes percepções de grupos de estudantes sobre a política de cotas em uma universidade pública. Essa técnica foi utilizada na segunda parte da análise dos dados.

Nossa lente teórica para compreensão dessa realidade é o referencial de transição de Schlossberg (1981, 1984). Em linhas gerais, assumimos que a transição se caracteriza como um evento ou não evento que resulta em mudanças na nossa rotina, pressupostos, papéis e na forma como estabelecemos relacionamentos com outros e com o meio (Andersson, Godman, \& Schlossberg, 2012), o que nos parece compatível com o que tem sido observado durante esse período de manifestação da Covid-19.

\section{Participantes}

Os participantes foram escolhidos por conveniência. Eles eram os orientadores de estágio em organizações com as quais os autores estavam em contato no momento de início da pandemia. Ao mesmo tempo, eram também os profissionais responsáveis pela gestão de pessoas em suas organizações. Abaixo apresentamos um breve perfil de cada um deles.

Psi 1: Psicóloga, 12 anos de formada, há oito anos especialista em POT. Fez estágio na área em 2008 (na própria empresa onde hoje trabalha), em 2009 foi admitida como Psicóloga (2009-2011) e dois anos depois foi selecionada por uma empresa de Engenharia, onde permaneceu por três anos desenvolvendo atividades de Recrutamento e Seleção. No ano de 2015, retorna à empresa onde fez estágio como Analista de RH e em 2018 foi promovida à gestora. Relata não ter interesse em sair da área. Atualmente, coordena uma equipe composta por profissionais de diversas áreas como: comunicação, psicologia e matemática.

A empresa tem como objetivo a criação e o desenvolvimento de soluções em softwares e atua principalmente para o setor público. Criada em 2001, oferece soluções em outsourcing e software, além de disponibilizar mão de obra especializada em TI (técnico de informática), treinamento e suporte para os gestores públicos e suas equipes. Atualmente possui mais de 700 colaboradores em todo o estado. Até o momento de realização deste estudo, não havia realizado desligamentos por conta da pandemia.

Psi 2: Psicóloga, formada há sete meses, fez estágio em uma consultoria de $\mathrm{RH}$, mas, ao final de 2019, já foi contratada pela empresa na qual atua atualmente, a partir do encaminhamento da consultoria que estagiava. Está registrada como analista de $\mathrm{RH}$, mas atua como gestora. Tem interesse em fazer pós-graduação em POT e se manter na área. Inicialmente, foi contratada em um regime de $40 \mathrm{~h}$ semanais que, devido à pandemia, foi reduzido para $20 \mathrm{~h}$ semanais e, posteriormente, retornado para $40 \mathrm{~h}$ semanais em 02 de junho de 2020.

Ela atua em uma rede de fast food (franquia), administrada por um grupo familiar que atua no mercado local desde 2005. No momento, contam com seis unidades no município. Tem como princípio "Pessoas são nosso maior talento". Hoje, empregam 130 pessoas, em grande parte jovens que estão em seu primeiro emprego. De março a julho de 2020 , realizaram uma redução de $30 \%$ no quadro de funcionários.

Psi 3: Psicólogo, formado há sete meses e, durante a formação em psicologia, já havia estagiado na empresa na qual trabalha atualmente. No mês 
de julho completou sete meses de carteira assinada. Foi registrado como Analista de Recursos Humanos, subordinado a uma psicóloga que se desligou da organização um mês antes da pandemia e, assim, mesmo como analista, acabou assumindo a gestão de pessoas. Pretende continuar na área até conseguir aprovação em um concurso público, que sempre foi seu objetivo profissional.

A organização tem cinco sócios e atua no ramo do Direito desde 2001, nas áreas de recuperação de crédito judicial/extrajudicial e contencioso cível, com ênfase na defesa dos interesses de instituições financeiras, seguradoras e pessoas jurídicas em geral. Atua em quatro estados do país e possui atualmente 70 funcionários. Tem como valores centrais "Pessoas em primeiro lugar, honestidade, capacidade técnica, bom relacionamento interpessoal, comprometimento, ética, confidencialidade". Encontra-se em dificuldades financeiras, tendo dificuldade de manter os salários de todos os funcionários em dia há mais de seis meses.

\section{Análise e discussão}

A perspectiva da transição dirige nosso olhar para a forma como os eventos se desdobram em uma dimensão temporal. Assim, é por aqui que começamos nosso percurso analítico, buscando identificar elementos que nos permitam compreender sua influência sobre a atuação dos profissionais de psicologia nas organizações de trabalho durante a pandemia. Essa posição é compatível com a perspectiva adotada, uma vez que segundo Andersson et al. (2012), só é possível compreender pessoas em transição se as estudarmos em diversos momentos no tempo.
Não há dúvida de que as experiências individuais são únicas. Entretanto, a partir do conjunto dos registros dos diários foi possível perceber uma sequência básica de eventos discretos, de natureza disruptiva, que são comuns aos três casos analisados. Essa estrutura comum nos remete ao fato de que as transições individuais acontecem no contexto de outras transições de nível mais elevado, que ocorrem na organização e na sociedade. Em outras palavras, temos transições dentro de transições que, em um momento qualquer, vão se superpondo e, muitas vezes, se confundido. Isso também sugere que a atuação do profissional que ocorre em um contexto é constrangida por elementos sobre os quais ele tem pouco ou nenhum controle, mas que afetam de forma significativa suas possibilidades de atuação. Nessa mesma direção, não é possível avaliar adequadamente aquilo que se passa com o indivíduo sem que estejamos atentos ao que acontece na organização e na sociedade.

Desenvolvemos nossa exposição a partir da identificação desses eventos que, funcionando como gatilhos, disparam processos de transição com todas as suas consequências. Esses eventos se apresentam como um fato ou uma ação identificável, se caracterizando como um divisor de águas em relação à forma como o trabalho vinha sendo executado até então. Existe um antes e um depois. No âmbito de uma organização de trabalho, assim que uma transição se inicia, as pessoas são obrigadas a lidar com ela, lançando mão dos recursos pessoais e institucionais que estão disponíveis. A Figura 2 abaixo mostra a sequência desses eventos principais. Uma primeira observação já deixa claro que, ao longo do período desse estudo, os participantes experimentaram múltiplas transições.

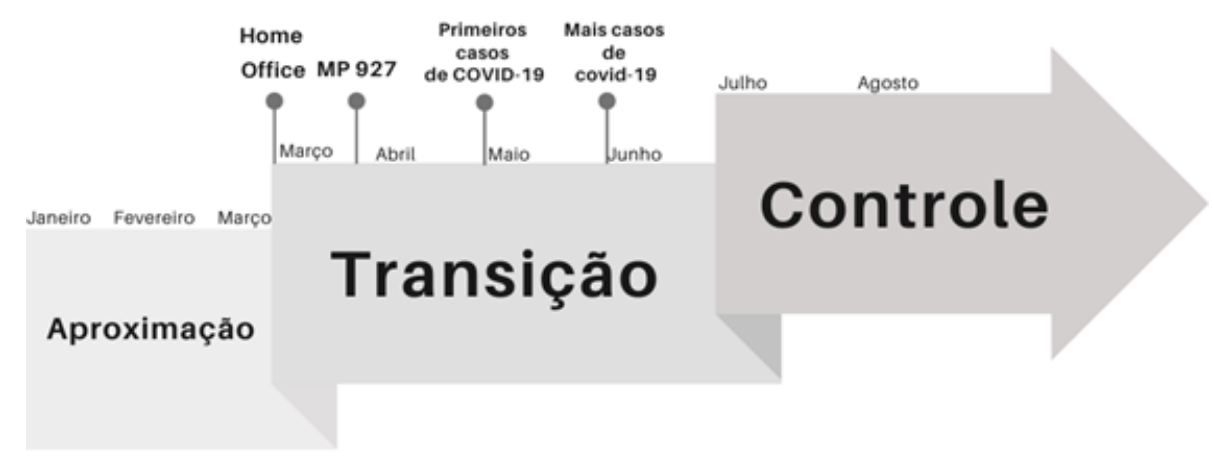

Figura 2.

Síntese do processo de transição durante a pandemia. 
O primeiro evento/gatilho identificado surge no dia 16 de março, quando um decreto municipal estabeleceu a suspensão dos trabalhos e determinou o isolamento social no município. Até esse momento, trabalhava-se como uma perspectiva de que esse tipo de medida eventualmente seria necessário, mas não havia uma indicação clara de quando isso se daria. Tem-se a impressão de que as empresas e profissionais não usaram esse momento inicial, de aproximação, para uma avaliação e um planejamento do que poderia vir a ser feito em caso de um agravamento da situação sanitária. Se houvessem procedido dessa maneira, certamente parte significativa das consequências psicossociais posteriormente observadas teriam sido evitadas ou, pelo menos, amenizadas. Com isso, aquilo que poderia ter sido uma transição antecipada, na prática, se apresentou com todas as características de uma transição não antecipada. A esse respeito, Anderson et al. (2012) nos lembram que a não preparação para situações inesperadas tem sido uma característica bastante comum em condições de desastres naturais, mesmo em situações nas quais existe a probabilidade que elas ocorram.

Apesar do noticiário sobre a pandemia, é a necessidade de suspender as atividades presenciais e mover os trabalhadores para home office que se apresentou como um evento disruptivo. Os psicólogos se sentem perdidos e desorientados. Suas práticas tradicionais já não se aplicam da mesma forma. Essa situação vem acompanhada por insegurança, medo e tensão, elementos que, em alguma medida, estão presentes por todo o período investigado ainda que em diferentes graus de intensidade.

. . começou com essa ideia repentina da gente ficar em home office né? De ficar em isolamento. Foi tudo muito repentino. E eu acho que na minha cabeça isso ainda era distante de se destacar e aí de repente a gente ficou... Foi assim em uma semana a gente falou: "a gente precisa começar a olhar para isso, precisa começar a pensar para caso isso aconteça aqui, para ver como é que a gente vai agir... E aí na outra semana a gente já na segunda-feira já conversamos para na terça-feira já estar todo mundo em home office, então, esse começar a planejar nem aconteceu a gente já do dia pra noite já colocamos todo mundo em home office... (Psi 1).

De início, um pouco perdida, bem perdida (Psi 2).
... quando rolou a pandemia eu tava aí com três meses de atuação aqui, né. Muito pouco tempo, né? Aqui sozinho. Quando... Logo quando começou o home office, no dia 17 de março. Aí que aconteceu a resolução, né? Num lembro de cabeça agora, mas quando saiu a resolução a gente já colocou o quadro inteiro de funcionários para home office. Então, os primeiros 15 dias aí foram bem complicados, né (Psi 3).

Imediatamente, os psicólogos passam a experimentar pressões contínuas devido à necessidade de acomodar as inúmeras e imprevisíveis demandas no ambiente de trabalho. A incerteza, o medo e o desconforto dos trabalhadores são relatados pelos profissionais, assim como, a necessidade de que ações alternativas de contato e acompanhamento aos funcionários fossem definidas.

Ai meu deus e agora? $O$ que eu faço com meus filhos? Então, foi um momento de bastante insegurança (Psi 1).

Os atendentes estavam com muito medo, tentei acalmá-los. Uma colaboradora pediu para o RH verificar se ela estava no grupo de risco e se precisaria ir embora, perguntei para o gerente e ele disse que se ela não estava sentindo nada, ela deveria ficar trabalhando, orientei o gerente a conversar com ela (Psi 2).

Tá sendo muito difícil é isso... Eu preciso confessar para vocês que está sendo bem complicado. Eu tenho 35 pessoas trabalhando aqui, mais 30 pessoas trabalhando no home office, aí tem as filiais. Então, eu tenho que dar atenção para todos... Eu tenho que dar atenção para todos de uma maneira diferente. Então, tem dias que eu passo quatro horas dentro dessa sala fazendo videochamada com quem 'tá em casa e tem dia que eu... Fico o dia inteiro lá conversando com a galera, eu mando mensagem: "como é que você tá?" e fico estimulando pra galera falar comigo também (Psi 3).

A transição desencadeia nos indivíduos um processo de mobilização de recursos institucionais e pessoais (coping) que lhes permitam lidar com a situação de alguma forma, ao mesmo tempo em que tentam estabelecer algum grau de controle e de estabilidade 
em relação ao processo de transição. Nesse ambiente conturbado e confuso, e diante da falta de experiência com situações semelhantes, o comportamento das organizações e dos profissionais assume um caráter reativo. Existe a expectativa de que venha do governo um conjunto de orientações e instruções sobre como proceder. Afinal, a relação de emprego é regulada por um conjunto legislativo específico que precisa ser observado sob pena de sanções. Entretanto, o que se vê nesse período inicial foi uma ação desordenada e descoordenada das diversas instâncias do poder público, o que amplificou a confusão ao invés de reduzi-la. Logo no dia 22 de março é publicada uma medida provisória (MP 927), a primeira de uma série, tratando de questões trabalhistas. Ela previu, entre outras coisas, a possibilidade de suspensão ou redução temporária de contratos e desligamentos. No período que se segue, ela foi repetidamente contestada, alterada e substituída, sendo finalmente revogada pela Ação Direta de Inconstitucionalidade no 6377 , no dia 8 de maio de 2020.

Começamos a analisar a MP 927 para avaliar quais medidas poderiam ser adotadas pela empresa. Muitas inseguranças começam a surgir nesse momento, afinal, a situação política do país também tem deixado o momento mais difícil, já que as definições estavam mudando muito rapidamente (Psi 1).

De início, um pouco perdida, bem perdida... O prefeito estava dando muito decreto um em cima do outro, então era uma mudança todo dia (Psi 2).

. . . o próprio banco não nos permitiu liberar os colaboradores para o HO, por questões de segurança de informação e por conta da LGPD (Lei Geral de Proteção de Dados) alguns continuam o trabalho in loco. Estes últimos dias estão sendo de muita reflexão sobre o momento da empresa, sobre o país e sobre minha competência como profissional (Psi 3).

Ao não prover os elementos necessários para estabilizar a situação, a ação do governo pode ser lida como outro evento disruptivo dessa dinâmica, desencadeando um novo processo de transição. Nesse contexto, aumentam as pressões sobre o trabalhador, inclusive com demissões e afastamentos. Começamos a perceber que as possibilidades dos psicólogos de lidar com a situação têm relação direta com a natureza do trabalho. Eles começam a ser mais demandados e passam a sentir o impacto dessa situação. Entretanto, a forma de lidar com essa realidade é modulada pela natureza do trabalho. Nesse momento, percebemos as primeiras diferenças no trabalho realizado pelo profissional de psicologia em relação ao que antes eles faziam, que adquire mais ou menos amplitude em função de características específicas da organização na qual ele atua.

. . entramos em um movimento de 'não demita' enquanto a gente podia para segurar as pessoas, para não demitir as pessoas. Usando de todos os recursos que a gente poderia, de acordo com as MPs que foram lançadas né, tudo que a gente poderia suspender a gente suspendeu... Férias que a gente podia dar de acordo com a MP, né, para pagar só lá no fim do ano com o décimo terceiro, a gente fez (Psi 1).

Foi o momento que nós tivemos alguns desligamentos, alguns não, vários ${ }^{1}$, então, eles tiveram que planejar esses desligamentos, as férias do pessoal que ia tirar férias ou não ia, pessoal que foi desligado, pessoal que ia entrar na redução, aí também teve a questão de que a redução não estava muito clara como iria acontecer, como as empresas deveriam fazer... Eu ajudei a fazer alguns desligamentos e algumas férias... Os colaboradores começaram a se comunicar por um grupo de Whatsapp e quando ligávamos para eles irem assinar o aviso, eles não atendiam e desligavam o celular, uma colaboradora relatou que "depois que falaram no grupo que estavam mandando todos embora, ninguém mais quis atender o telefone" (Psi 2).

Recordamos que a Psi 1 trabalha em uma empresa de informática e, nesse caso, a passagem para o home office ocorreu de forma mais suave, uma vez que o tipo de atividade realizada permitia sua realização à distância sem grandes perdas de continuidade. Já a Psi 2 trabalha em uma cadeia de lojas de alimentação (fast food) que, em um primeiro momento, perdeu grande parte de seu faturamento em função do fechamento

${ }^{1}$ Quarenta funcionários da área operacional foram demitidos em função do fechamento das lojas onde trabalhavam. 
de suas lojas físicas. Por sua vez, o Psi 3 trabalha em uma empresa em que parte das atividades pode ser realizada à distância e parte precisa ser realizada no local de trabalho em função de restrições legais.

Nesse momento, começam as ações de acompanhamento e de acolhimento relacionadas à saúde do trabalhador. Fatores como cultura e natureza do processo de trabalho interagem e são determinantes para a compreensão da atuação profissional.

Começamos uma campanha incentivando que os colaboradores que têm direito tomassem a vacina da gripe pelo SUS... Para os colaboradores que precisavam se deslocar até o trabalho, disponibilizamos Uber... Conseguimos comprar as doses da vacina para imunizar as pessoas da sede... Começamos a fazer um levantamento de quantas gestantes temos na empresa e quais ainda estavam trabalhando para colocá-las em home office. Tudo isso exige da gente negociação com nossos clientes... Fizemos uma live ... reforçamos . . . a intenção da empresa em não demitir as pessoas... Estamos confeccionando máscaras e mais álcool em gel para distribuir para nossos colaboradores; começamos uma ação para vacinar todos os colaboradores do interior... Fizemos um bate papo sobre psicologia e saúde com nossos colaboradores (Psi 1).

Começam a ser distribuídos máscaras que serão utilizadas como uniforme; verificação de orçamento de termômetros para aferir a temperatura dos colaboradores; orientação para os gerentes da loja sobre as medidas de segurança para a loja; treinamento para os gerentes assistentes sobre liderança, mudanças e o papel deles diante disso... O gerente de negócios fez o RH vivenciar as dificuldades encontradas em utilizar luva para o caixa (a luva dificulta o uso do caixa), montagem do pedido (ao fechar as sacolas com o adesivo, a luva gruda no adesivo e acaba rasgando ambos e tendo que ser trocado) e ao retirar refrigerante da máquina (o copo escorrega da mão e pode cair no chão). Uma colaboradora procurou o RH para comunicar que iria pedir demissão pois as coisas estão "muito estranhas, tudo bagunçado"(Psi 2).

Um vídeo do Diretor no Whatsapp de todos os funcionários, falando sobreo Covid, tranquilizando-os a respeito do futuro e pedindo feedback sobre o trabalho... Estive em contato com os colaboradores... a equipe negocial da carteira dos bancos $x e$ y retornaram o trabalho in loco, devido a algumas exigências desses clientes. Fui ao escritório para auxiliá-los, averiguar a necessidade de cada um, como estavam se sentindo com o retorno... Desde então, passei a ir alguns dias ao escritório para assistir os funcionários e também para escapar de casa um pouco (Psi 3).

Com a continuação do isolamento social e a necessidade de compatibilização do funcionamento das organizações, os profissionais da psicologia se depararam com a necessidade de reestruturar suas ações, estabelecer uma rotina, agora adaptadas a um novo formato. O prolongamento da situação impõe a necessidade de desenvolvimento de estratégias adaptativas que permitam o estabelecimento de algum grau de normalidade e rotina sobre o funcionamento. Os profissionais de POT lançam mão de diversas estratégias de coping, ao mesmo tempo que se envolvem mais profundamente no cotidiano da gestão de seus espaços de trabalho.

.. conversar com a minha equipe e com as pessoas da minha empresa. A gente faz muita pesquisa e conversa muito para entender quais as necessidades delas naquele momento e tentar dialogar com a gestão de pessoas naquele momento para a gente conseguir adaptar de uma forma que fosse bom para os dois lados. E também trazer um pouco de transparência para as pessoas, tudo que a empresa vem fazendo nesse momento para que a gente possa manter a empresa funcionando $e$ manter os beneficios que eles tinham, né? (Psi 1).

Estudos da literatura cientifica dos impactos dos desligamentos (Psi 2).

A gente fica praticamente o dia inteiro com essa troca de informações aí. Não somente a respeito de trabalho, a gente conversa muito um com o outro sobre saúde mental, indicando texto pro outro ler, live pra gente assistir junto. Então, vejo que isso também faz... como posso colocar... meio que me ajuda mesmo a ter essas reflexões sobre trabalho... A gente sai da universidade achando que sabe algo... Agora mais do que nunca vejo a necessidade de estudar e fazer uma pós... (Psi 3). 
Apesar de toda crise, percebe-se que existe espaço para melhoria, aprendizagem e crescimento. Assim como para um maior reconhecimento do papel da psicologia no contexto organizacional. O psicólogo passa a atuar de forma mais próxima aos gestores das empresas, tornando-se protagonista no processo de gestão, a partir da orientação das ações e práticas gerenciais.

O setor de gestão de pessoas é acionado diariamente para decisões estratégicas, o diálogo com a diretoria é constante e sempre muito transparente... enfim. Eu sinto que a situação está melhorando, a passos curtos, mas eu enxergo mudanças comportamentais nos gestores... Estou trabalhando com eles a questão de autorregulação emocional. Prevejo melhoras significativas, pois reclamavam muito de dor de cabeça de tanto pensar, insônia, preocupação excessiva, vida pessoal turbulenta... (Psi 3).

Ainda que medidas de proteção tenham sido tomadas e algum tipo de suporte tenha sido oferecido aos empregados, o medo, a insegurança e a falta de informação cobram seu preço. É possível verificar que sintomas de adoecimento mental no trabalho começam a aparecer nas organizações.

Uma colaboradora da minha equipe, que trabalha na área de saúde e segurança do trabalho, teve sintomas de estresse e ansiedade e por isso irá se afastar por 10 dias.... (Psi 1).

... Gerente passa mal com sintomas de ansiedade (Psi 2).

. . . Nesses dias, mantive contato diário com os funcionários. Noto que muitos estão tendo dificuldades em relação à concentração, ergonomia e também dificuldades emocionais por conta do isolamento (Psi 3).

Quando já parece que há um domínio sobre o trabalho diante dessa nova dinâmica imposta pela pandemia, a suspeita ou mesmo a confirmação dos primeiros casos diagnosticados nas equipes interrompe momentaneamente o processo de acomodação que estava em curso, gerando um novo momento disruptivo. Aumenta o medo entre os trabalhadores, agora pela proximidade da doença. Entretanto, a recém-construída familiaridade com a atual situação e um maior domínio sobre como atuar fazem com que a intensidade e o impacto desse episódio sobre o trabalho e sobre os trabalhadores seja diminuído e mais facilmente assimilado.

Tivemos a notificação do primeiro caso confirmado entre nossos colaboradores. Fizemos o acompanhamento do caso. A colaboradora já estava em quarentena por ser grupo de risco... Um outro caso positivo onde a colaboradora foi orientada a ficar em quarentena (Psi 1).

RH começa a sentir sintomas de gripe como tosse, espirros e febre, foi realizado uma consulta online na plataforma de atendimento . . e e a orientação foi ficar em isolamento em casa. Foi passado para a diretoria, ela disse para ficar realizando as atividades em home office e parar as visitas nas lojas. Primeiro caso de colaborador que teve contato com caso positivo, apresentou um atestado de um médico dizendo que não havia necessidade de realizar o teste. Segundo caso de contato direto com confirmados de Covid, colaboradora da loja P, está afastada. Orientações para os gerentes assistentes e gerentes de negócio da loja sobre o caso do colaborador (Psi 2).

A pessoa me ligou para dizer que testou positivo para o Covid-19... Tive que me mobilizar quase que de imediato... Depois de trazer a informação ao Boss e aos demais gestores, de forma transparente e bem assertiva, optamos por retornar o home office com todos que compartilhavam o mesmo ambiente que ela. Vale destacar que nenhum estava com sintomas, mas, como medida de prevenção, pedimos para retornarem para casa e ficarem em observação. Até o presente momento quatro colaboradores, que tiveram contato direto com a funcionária que havia contraído o vírus, realizaram o teste do Covid e todos deram negativo. Essa notícia tranquilizou instantaneamente as pessoas aqui. Trouxe um pouco de alegria e alívio a todos nós (Psi 3).

Pela posição que ocupam, os profissionais da psicologia percebem de forma clara tanto as demandas e as questões de pessoal, quanto os problemas e as questões que impactam mais diretamente a 
organização. Esse lugar impõe uma carga de pressão que é sentida pelos profissionais de POT. Eles, que tanto se conectaram com as pessoas, precisam de apoio e de suporte.

Eu, no começo, foi bem difícil para mim porque ao mesmo tempo que eu tinha que lidar com tudo isso que estava acontecendo dentro da empresa, a insegurança das pessoas, medo de serem demitidas, porque tinha muita gente com medo de ser demitida né, porque começou a demissão em massa. Eu também sou trabalhadora, também sou pessoa, também estava com meus filhos em casa, na loucura, então no começo assim, foi bem difícil saber conciliar tudo isso e saber equilibrar as necessidades da empresa e as necessidades das pessoas, né. Tinha hora que eu me via no fogo cruzado ali porque a empresa tinha as necessidades dela ali, até na questão de orçamento, e eu na gestão de pessoas, tinha as minhas necessidades ali da área que eu precisava dar um jeito de fazer acontecer. Então, foi bem complicado até que a gente conseguisse se adaptar foi bem estressante (Psi 1).

... todo mundo muito comovido... muita dúvida, muita insegurança (Psi 2).

.. Nestas últimas semanas eu não consegui ter boas noites de sono, veio à tona muitas memórias e pensamentos que me incomodam... Engraçado é que me pedem orientações para lidar com isso, e como orientar sobre algo que nem eu estou conseguindo lidar direito? Tá complicado, muitas dúvidas surgem... (Psi 3).

Como podemos observar, a pandemia se apresenta com as características de um evento não antecipado, trazendo consigo sentimentos de medo e de insegurança. Em um primeiro momento, há uma expectativa de que recursos sociais e organizacionais sejam mobilizados para apoiar o processo de transição, trazendo um maior controle sobre o trabalho. A ação errática e descoordenada da esfera pública parece ter resultado na ampliação da confusão, por não oferecer definições e indicações que permitam lidar com esse período de forma mais suave. As organizações que, por sua vez, também enfrentam uma transição e se sentem igualmente ameaçadas, possuem recursos e possibilidades distintas de enfrentamento da crise. Sua capacidade de lidar de forma melhor ou pior com a transição tem relação com o tipo de trabalho que ela realiza e a forma como ela se encontra organizada. Isso pode ser percebido, por exemplo, na forma como os relatos dos diários se encontram estruturados.

No caso 1 , já havia antes da pandemia uma preocupação com a saúde dos empregados, o que se manifestava na realização de campanhas anuais de saúde. Além disso, essa era uma empresa maior, que dispunha de uma equipe de RH mais ampla. Isso parece ter permitido à Psi 1 relatar um foco mais específico com os cuidados de saúde. Por outro lado, a atividade principal dos trabalhadores dessa empresa podia ser transferida para o mundo virtual sem grandes dificuldades. Isso fez com que o relato da profissional de psicologia tenha um foco muito grande na questão do suporte à saúde física e mental dos funcionários. Assim, a etapa de controle parece ter se apresentado mais cedo do que nos outros dois casos.

Já no caso 2, parece existir uma preocupação mais ligada às questões operacionais, relacionadas ao que costumamos chamar de departamento de pessoal. Os registros são feitos com base em ações que são realizadas no cotidiano. Estamos falando aqui de uma cadeia de fast food, em que o trabalho depende de sua localização em um espaço físico específico e afetada economicamente pelo confinamento compulsório de seus clientes/consumidores. Ainda que a preocupação com a saúde dos empregados também esteja presente, existem menores possibilidades de trabalho remoto, o que se manifesta nas demissões. As ações de cuidado com a saúde estão mais relacionadas às questões operacionais e indicadas pelo poder governamental, notadamente o uso de equipamentos de segurança que diminuam o risco de contaminação.

Já no caso 3, parece que temos uma situação intermediária. Algumas atividades precisam ser localizadas no espaço físico, pela natureza da atividade executada, e outras podem ser desenvolvidas no mundo virtual. Aqui o profissional de psicologia se vê às voltas tanto com questões de saúde e suporte emocional quanto questões operacionais.

É interessante observar que, em meio à transição no ambiente de trabalho causadas pela pandemia, outras transições subsequentes vão se apresentando 
de forma simultânea e que, certamente, permitem melhor compreender os limites e as possibilidades de atuação do profissional. É o vemos, por exemplo, no caso 3. Em meio à pandemia, a empresa mudou sua localização, saindo de um espaço físico para outro. Da mesma forma, o Psi 3 assumiu a posição de gestor durante a pandemia, o que coloca pressão adicional sobre sua atividade e a necessidade de lidar com múltiplas transições, o que provavelmente exige recursos de coping mais significativos e variados.

No Quadro 1 abaixo apresentamos, de forma comparativa, como os psicólogos de POT percebem as principais alterações e mudanças na forma como eles realizam seu trabalho, na relação com os trabalhadores e uma indicação de qual foi seu maior desafio durante esse período.

Quadro 1.

Síntese das entrevistas individuais.

\begin{tabular}{|c|c|c|c|}
\hline Pergunta & Psi 1 & Psi 2 & Psi 3 \\
\hline $\begin{array}{l}\text { O que mudou } \\
\text { nas práticas de } \\
\text { atuação? }\end{array}$ & $\begin{array}{l}\text { "Acho que foi importante a } \\
\text { gente começar a olhar mais } \\
\text { para esse suporte emocional } \\
\text { que as pessoas precisam ter. } \\
\text { Se a pessoa tem hora positiva } \\
\text { ou negativa no banco de } \\
\text { horas, então isso eram } \\
\text { preocupações frequentes } \\
\text { da empresa que hoje não } \\
\text { acontece mais. Hoje dedica- } \\
\text { se mais tempo para entender } \\
\text { o propósito daquilo que a } \\
\text { gente está fazendo e fazendo } \\
\text { mais coisas com muito mais } \\
\text { propósito e um objetivo muito } \\
\text { mais claro com uma definição } \\
\text { real do resultado que a gente } \\
\text { deseja atingir.” }\end{array}$ & $\begin{array}{l}\text { “Antes a gente estava fazendo } \\
\text { descritivo de função, de } \\
\text { cargo, de todo mundo porque } \\
\text { existia um que era muito } \\
\text { desatualizado. Então, eu estava } \\
\text { fazendo isso e eu já tinha } \\
\text { montado todo um programa } \\
\text { de desenvolvimento da } \\
\text { liderança para gente iniciar } \\
\text { com eles e essa parte toda } \\
\text { foi deixada de lado. Agora, } \\
\text { a minha prática está muito } \\
\text { mais voltada para orientação } \\
\text { em questões de saúde } \\
\text { mesmo, de segurança deles e } \\
\text { relacionamento, respeito.” }\end{array}$ & $\begin{array}{l}\text { "O que eu mais senti } \\
\text { diferença foi a questão do } \\
\text { recrutamento e seleção. } \\
\text { É, eu tentei fazer duas } \\
\text { vezes de forma virtual. } \\
\text { Confesso que eu não me } \\
\text { senti de forma confortável, } \\
\text { não achei tão interessante." }\end{array}$ \\
\hline $\begin{array}{l}\text { Você percebe } \\
\text { diferença no } \\
\text { contato com os } \\
\text { trabalhadores? }\end{array}$ & $\begin{array}{l}\text { "Ficou mais complicado de } \\
\text { resolver as coisas que a gente } \\
\text { precisava resolver da forma } \\
\text { que a gente resolvia antes." }\end{array}$ & $\begin{array}{l}\text { “A gente já tinha uma diferença } \\
\text { muito grande de contato entre } \\
\text { a parte administrativa e a } \\
\text { parte da operação. Antes da } \\
\text { pandemia, eu já identificava } \\
\text { essa diferença, até que eles } \\
\text { falam assim quando você entra } \\
\text { 'você tem que escolher, o você } \\
\text { vai ser da operação ou você vai } \\
\text { ser do administrativo'. Então, já } \\
\text { tinha essa grande diferença, e } \\
\text { agora, isso se intensificou, até } \\
\text { o contato entre o pessoal da } \\
\text { operação com os atendentes } \\
\text { mudou, eles estão mais } \\
\text { receosos nesse contato. Eles } \\
\text { também têm muito medo de } \\
\text { mim, medo mesmo.” }\end{array}$ & $\begin{array}{l}\text { “É bem nítido a diferença, } \\
\text { é bem nítido mesmo. Por } \\
\text { que a galera que está em } \\
\text { casa, eles estão } 100 \% \text { em } \\
\text { isolamento mesmo. Então, } \\
\text { eles não saem, } \\
\text { não fazem nada. Eles estão } \\
\text { realmente cumprindo } \\
\text { toda a quarentena. Então, } \\
\text { quando você liga para } \\
\text { eles, a maneira como eles } \\
\text { recebem é bem diferente. } \\
\text { Eles são muito mais } \\
\text { receptivos, ficam super } \\
\text { felizes pela ligação.” }\end{array}$ \\
\hline $\begin{array}{l}\text { Qual foi seu } \\
\text { maior desafio } \\
\text { para atuação? }\end{array}$ & $\begin{array}{l}\text { "Foi fazer com que esse projeto } \\
\text { (descrição de cargos) que a } \\
\text { gente tinha previsto acontecer } \\
\text { diante de todo esse cenário." }\end{array}$ & $\begin{array}{l}\text { "Sem dúvidas lidar com todas } \\
\text { as mudanças e essa questão dos } \\
\text { desligamentos particularmente } \\
\text { foi bem difícil para mim." }\end{array}$ & $\begin{array}{l}\text { "Em relação à minha saúde } \\
\text { mental. Eu me manter } \\
\text { motivado a cuidar das } \\
\text { outras pessoas.” }\end{array}$ \\
\hline
\end{tabular}


Diante das respostas desses três profissionais, fica nítida a constatação da necessidade de adaptação de sua prática profissional e de como eles utilizaram os aprendizados desenvolvidos ao longo desse momento de crise para aperfeiçoar seu fazer e amplificar o impacto de sua atuação nas organizações. Os múltiplos momentos de transição vividos por esses três psicólogos organizacionais durante os primeiros meses de enfrentamento da pandemia demandaram a esses profissionais o desenvolvimento de competências que os qualificarão para atuarem de forma mais eficaz no futuro. Da mesma maneira, o passar do tempo evidencia um maior controle sobre as atividades de trabalho, o que se expressa pelo desenvolvimento de uma rotina.

\section{Conclusão}

A análise das características e dinâmicas da pandemia nos oferece a oportunidade de lançarmos luz sobre processos e variações vividos pelos profissionais participantes do estudo. Encontramos bem demarcada a mudança do foco de atuação: de aspectos mais técnicos e restritos, para questões mais amplas e coletivas. O evento de confinamento social imposto pela pandemia, apesar de ter impossibilitado a continuidade dos projetos e das ações da gestão de pessoas que estavam em andamento, desencadearam um processo de múltiplas transições no exercício profissional de psicólogos organizacionais e do trabalho.

Diante do momento de crise, os profissionais de psicologia tiveram que lidar com os medos e as ansiedade dos trabalhadores, com o risco de contaminação, com o fantasma das demissões, com as demandas dos gestores, além da incerteza do contexto político e econômico que, embora externos, impactam a organização. Além disso, tiveram que lidar com as próprias demandas pessoais e profissionais ao longo desse período: a dificuldade pessoal e contextual de se adaptar ao home office, o sentimento de impotência e a necessidade de buscar novos conhecimentos para criar ações que respondessem aos anseios dos trabalhadores.

Lidar com todo esse conjunto de situações inesperadas pode representar uma tarefa árdua e com muitas dificuldades. A combinação particularmente única de fatores como medidas governamentais, suporte organizacional e recursos pessoais tende a implicar na definição de ações e na tomada de decisão do profissional. Investir em ações de saúde, segurança e suporte psicossocial é uma das ações prioritárias na crise atual. Porém, os psicólogos organizacionais e do trabalho não se limitaram a isso e foram além. Diante de um contexto incerto e desafiador, é possível observar o desenvolvimento de competências dos psicólogos, bem como um crescente protagonismo da psicologia organizacional e do trabalho.

Apesar de ter sido originalmente proposto para avaliar processos individuais, o referencial de transição de Schlossberg $(1981,1984)$ se mostrou adequado para a análise do processo de transição vivido por profissionais da psicologia organizacional e do trabalho durante a pandemia. Nos casos apresentados, há claramente uma sucessão de eventos disruptivos que podem ser melhor ou pior manejados em função de interações que ocorrem entre recursos individuais e organizacionais

Vale ainda destacar que o uso de diários mostra que efetivamente existem variações importantes no comportamento dos indivíduos e interações contextuais que se processam ao longo do tempo, que não são capturados a partir da utilização de métodos tradicionais de pesquisa na área, como pesquisas do tipo survey. Nesse sentido, o uso de diários permite que pesquisadores e profissionais compreendam como os aspectos contextuais moldam o comportamento dos indivíduos, bem como as múltiplas flutuações que podem ocorrer em um dado período. Vale ressaltar que este estudo apresenta uma limitação importante em relação ao número limitado de casos investigados.

Buscamos nesse artigo ampliar as discussões sobre a prática profissional dos psicólogos, bem como sobre a integração das dimensões ciência e profissão, iluminando o fazer profissional à luz das teorias da POT. Destacamos a necessidade de estudos dessa natureza, a fim de diversificar as pesquisas em POT no Brasil, ainda mais diante de cenários turbulentos e inseguros. Há um vasto campo de investigação quanto ao potencial do psicólogo organizacional e do trabalho frente a mudanças disruptivas e gestão de crises.

Existem mudanças que precisamos fazer em nossas vidas profissionais tanto individuais quanto coletivas. Os relatos e as considerações mais proativos apontam para a necessidade de formular intervenções com práticas de liderança por parte 
do profissional psicólogo. A pandemia, a virtualidade e a disruptividade têm evidenciado o quão fundamental são competências como liderança, comunicação e gestão. O que aprendemos com a pandemia? Defendemos começar por nós mesmos.
Além das oportunidades de pesquisa, é importante discutir práticas baseadas em evidências na crise da pandemia e integrar o desenvolvimento de conhecimentos, habilidades e atitudes a nossa formação e atuação.

\section{Referências}

Abbad, G. S., \& Carlotto, M. S. (2016). Analyzing challenges associated with the adoption of longitudinal studies in work and organizational psychology. Revista Psicologia: Organizações e Trabalho, 16(4), 340-348. https://doi.org/ 10.17652/rpot/2016.4.12585

Anderson, M. L., Goodman, J., \& Schlossberg, N. K. (2011). Counseling adults in transition: Linking Schlossberg's theory with practice in a diverse world (4a ed.). New York: Springer Publishing Company.

Anderson, N., Herriot, P., \& Hodgkinson, G. P. (2001). The practitioner-researcher divide in industrial, work and organizational (IWO) psychology: Where are we now, and where do we go from here?. Journal of Occupational and Organizational Psychology, 74(4), 391-411. https://doi.org/10.1348/096317901167451

Baert, S., Lippens, L., Moens, E., Sterkens, P., \&Weytjens, J. (2020). The Covid-19 crisis and telework: A research survey on experiences, expectations and hopes. GLO Discussion Papers, (532), 1-37. https://econpapers.repec.org/ paper/zbwglodps/532.htm

Bastos, A.V. B., Gondim, S. M. G., \& Rodrigues, A. C. A. (2010). Uma categoria em expansão: quantos somos e onde estamos? In A. V. B. Bastos, \& S. M. G. Gondim (Orgs.), O trabalho do psicólogo no Brasil (pp. 32-44). Porto Alegre: Artmed.

Bastos, A. V. B., \& Rodrigues, A. C. A. (2014). Campo profissional do psicólogo em organizações e trabalho. In J. C. Zanelli, J. E. Borges-Andrade, \& A. V. B. Bastos (Orgs.), Psicologia, organizações e trabalho no Brasil (2a ed., pp. 466-491). Porto Alegre: Artmed.

Bentivi, D. R. C. (2020). Retrato da psicologia brasileira no cenário da Covid-19 (O trabalho e as medidas de contenção da Covid-19: Contribuições da psicologia organizacional e do trabalho no contexto da pandemia, vol. 3). Porto Alegre: Artmed.

Bolger, N. Davis, A., \& Rafaeli, E. (2003). Diary methods: Capturing life as it is lived. Annual Review of Psychology, 54, 579-616. https://doi.org/10.1146/annurev.psych.54.101601.145030

Breakwell, G. L. (2010). O uso do autorregistro: Métodos de diário e de narrativa. In G. M. Breakwell, S. Hammond, C. Fife-Shaw, \& J. A. Smith (Eds.), Métodos de pesquisa em psicologia (3a ed., pp. 260-277). Porto Alegre: Artmed.

Campos, K. C. L., Duarte, C., Cezar, É. O., \& Pereira, G. O. A. (2011). Psicologia organizacional e do trabalho: Retrato da produção científica na última década. Psicologia: Ciência e Profissão, 31(4), 702-717. https://doi.org/10.1590/ S1414-98932011000400004

Carnevale, J. B., \& Hatak, I. (2020). Employee adjustment and well-being in the era of Covid-19: Implications for human resource management. Journal of Business Research, 116, 183-187. https://doi.org/10.1016/j.jbusres.2020.05.037

Coelho-Lima, F., Costa, A. L. F., \& Yamamoto, O. H. (2011). O exercício profissional

do psicólogo do trabalho e das organizações: Uma revisão da produção científica. Revista Psicologia: Organizações e Trabalho, 11(2), 21-35. http://pepsic.bvsalud.org/pdf/rpot/v1ln2/v1ln2a03.pdf

Gondim, S. M. G., Bastos, A. V. B., \& Peixoto, L. S. A. (2010). Áreas de atuação, atividades e abordagens teóricas do psicólogo brasileiro. In O trabalho do psicólogo no Brasil (pp. 174-199). Porto Alegre: Artmed.

Hobsbawn, E. (1994). A era dos extremos: O breve século XX: 1914-1991 (2a ed.). São Paulo: Companhia das Letras.

Labrague, L. J., \& Los Santos, J. A. (2020). Covid-19 anxiety among frontline nurses: Predictive role of organisational support, personal resilience and social support. Journal of Nursing Management, 28(7), 1653-1661. https://doi.org/10.1111/jonm.13121

Molino, M., Ingusci, E., Signore, F., Manuti, A., Giancaspro, M. L., Russo, V., Zito, M., \& Cortese, C. G. (2020). Wellbeing costs of technology use during Covid-19 remote working: An investigation using the italian translation of the technostress creators scale. Sustainability, 12(15), 5911. https://doi.org/10.3390/su12155911 
Moraes, M. M. (2020). Os impactos da pandemia para o trabalhador e suas relações com o trabalho (O trabalho e as medidas de contenção da Covid-19: Contribuições da psicologia organizacional e do trabalho no contexto da pandemia, vol. 2). Porto Alegre: Artmed.

Novitasari, D., Sasono, I., \& Asbari, M. (2020). Work-family conflict and worker's performance during Covid-19 pandemic: What is the role of readiness to change mentality? International Journal of Science and Management Studies, 3(4), 122-134. https://ijsmsjournal.org/2020/volume-3\%20issue-4/ijsms-v3i4p112.pdf

Ohly, S., Sonnentag, S., Niessen, C., \& Zapf, D. (2010). Diary studies in organizational research. Journal of Personnel Psychology, 9(2), 79-93. https://doi.org/10.1027/1866-5888/a000009

Pearson, C. M., \& Clair, J. A. (1998). Reframing crisis management. Academy of management review, 23(1), 59-76. https://doi.org/10.2307/259099

Peixoto, A. L. A., \& Bastos, A. V. B. (2019). Organizações. In P. Bendassolli, \& J. E. Borges-Andrade (Orgs.), Dicionário de psicologia do trabalho e das organizações (pp.491-500). Belo Horizonte: Artesã.

Peixoto, A. L. A, Côrtes, V. N. Q., \& Bastos, A.V. B. (2020). Do ensino superior para o mercado de trabalho: Desafios da transição. In A. B. Soares, L. Mourão, \& M. C. Monteiro (Orgs.), O estudante universitário brasileiro: Saúde mental, escolha profissional, adaptação à universidade e desenvolvimento de carreira. Curitiba: Appris.

Queiroga, F. (2020). Orientações para o home office durante a pandemia da Covid-19 (O trabalho e as medidas de contenção da Covid-19: Contribuições da psicologia organizacional e do trabalho no contexto da pandemia, vol. 1). Porto Alegre: Artmed.

Renteria, E., Peixoto, A. L. A, \& Bastos, A. V. B (2020). Producción de conocimiento, práctica profesional y formación en psicología de las organizaciones y del trabajo: Desafíos presentados por el contexto latinoamericano. In J. Orejuela (Ed.), Desafios en la formación de psicólogos de las organizaciones y el trabajo. Medellin: Editorial EAFIT.

Ribeiro, E. M. A, Peixoto, A. L. A., \& Bastos, A. V. B. (2019). Relações intergrupais e sistema de cotas: Percepções de estudantes de direito. Revista Brasileira de Orientação Profissional, 20(2), 3-15. https://doi.org/10.26707/1984-7270/2019v20n2p3

Schlossberg, N. K. (1981). A model for analyzing human adaptation to transition. The Counseling Psychologist, 9(2), 2-18. https://doi.org/10.1002/j.2161-1920.2011.tb01102.x

Schlossberg, N. K. (1984). Counseling adults in transition: Linking practice with theory. New York: Springer Publishing.

Sonnentag, S. (2012). Time in organizational research: Catching up on a long neglected topic in order to improve theory. Organizational Psychology Review, 2(4), 361-368. https://doi.org/10.1177/2041386612442079

Strauss, A. L. (1987). Qualitative analysis for social scientists. Cambridge: Cambridge University Press.

Wiedemann, C. (n.d.). The great transformation? The cultural implications of Covid-19. Barret Values Centre. https://www.valuescentre.com/resource-library/covid/

Yin, R. K. (2009). Case study research: Design and methods. Thousand Oaks: Sage Publications.

\section{Adriano de Lemos Alves Peixoto}

Doutor pela Universidade de Sheffield (Inglaterra) e docente do Programa de Pós-Graduação em Psicologia da Universidade Federal da Bahia, Salvador - BA. Brasil.

E-mail: peixoto@ufba.br

(1) https://orcid.org/0000-0003-1962-1571

\section{Eveli Freire de Vasconcelos}

Doutora em Psicologia pela Universidade Católica Dom Bosco. Docente e pesquisadora do curso de Psicologia da UCDB, Campo Grande - MS. Brasil.

E-mail: evelivasconcelos@yahoo.com.br

(1) https://orcid.org/0000-0001-5140-760X 


\section{Daiane Rose Cunha Bentivi}

Doutora em Psicologia pela Universidade do Porto (Portugal). Pesquisadora do Programa de Pós-Graduação em Psicologia da Universidade Federal da Bahia, Salvador - BA. Brasil.

E-mail: daianebentivi@hotmail.com

(D) https://orcid.org/0000-0002-6944-5476

Endereço para envio de correspondência:

Instituto de Psicologia da Universidade Federal da Bahia. R. Prof. Aristídes Novis, 197, Federação. CEP: $40210-730$.

Salvador - BA. Brasil.

Recebido 02/10/2020

Aceito 02/ 10/20200

Received 10/02/2020

Approved 10/02/2020

Recibido 02/10/2020

Aceptado 02/10/2020

Como citar: Peixoto, A. L. A., Vasconcelos, E. F., \& Bentivi, D. R. C. (2020). Covid-19 e os Desafios Postos à Atuação Profissional em Psicologia Organizacional e do Trabalho: uma Análise de Experiências de Psicólogos Gestores. Psicologia: Ciência e Profissão, 40, 1-18. https:// doi.org/10.1590/1982-3703003244195

How to cite: Peixoto, A. L. A., Vasconcelos, E. F., \& Bentivi, D. R. C. (2020). Covid-19 and the Challenges Posed to Organizational and Work Psychologists: an Analysis of the Experiences of Psychologists in Managerial Positions. Psicologia: Ciência e Profissão, 40, 1-18. https:// doi.org/10.1590/1982-3703003244195

Cómo citar: Peixoto, A. L. A., Vasconcelos, E. F., \& Bentivi, D. R. C. (2020). Covid-19 y los Retos del Desempeño Profesional en Psicología Organizacional y del Trabajo: un Análisis de las Experiencias de los Psicólogos Directivos. Psicologia: Ciência e Profissão, 40, 1-18. https://doi.org/10.1590/1982-3703003244195 